\title{
Analysis of Strategic Emerging Industrial Policies on the Level of Central Government in China
}

\author{
Rui Sun'1, Jinxi Wu', Baojuan Liu² \\ ${ }^{1}$ Institute of Science, Technology and Society, School of Social Sciences, Tsinghua University, Beijing, China \\ ${ }^{2}$ School of Foreign Languages, Hebei University of Science and Technology, Shijiazhuang, China \\ Email: sunr07@mails.tsinghua.edu.cn
}

Received May 2014

\begin{abstract}
40 samples are selected from the collected China's strategic emerging industry (SEI) policies on the level of central government from 2010 to 2013, and policy content analysis is applied to conduct a textual and quantitative research on them. Through constructing a two-dimensional analytical framework of "industry development dimension" and "policy support dimension", this paper makes a statistical analysis on the frequency of certain words counts in China's SEI policies. The results show that China's SEI policies are characterized as focused keywords, innovation as the first key element, excessive planning and insufficiency of demand-based policy.
\end{abstract}

Keywords

Strategic Emerging Industry (SEI), Industrial Policy, Content Analysis, Keywords, Coding

\section{Introduction}

In 2010, China's State Council issued the Decision on Accelerating the Fostering and Development of Strategic Emerging Industries (the SEI Decision) ([2010] 32), according to which new energy, new materials, energy saving and environmental protection, new-energy vehicles, new-generation information technology, high-end equipment manufacturing and biotechnology are identified as seven strategic emerging industries. The country planned to increase the share of these industries' total added-value in its GDP to around 8 percent by 2015 and 15 percent by 2020 [1]. Since then, the Chinese SEI policy system including policies at the national and local level, objective programming, developmental plans and specific measures have been improved.

\section{Literature Review}

The academic literature studies Chinese SEI policies from various perspectives. According to research focus, the classification of SEI policies varies. Categorized by stage, the policy evolution is divided into the preparation stage and the overall start-up stage [2]. According to the policy field, the existing policies include industrial and technological policy, market cultivation policy, international cooperation policy, industrial investment and fi- 
nancing policy, tax policy and policies in other special fields [3]. The policy instruments consist of four groups, that is, strategic plans, specific measures, support policies, and organization safeguards [4]. Some latest reviews and evaluations of SEI policies focus on the aspects of the role of government, regional distribution, mode of development, as well as the relationship with finance and other industries [5]. As is often the case with policy decision-making and implementation in China, the central government drafts general guidelines and local governments handle direct implementation. Therefore, the local governments play a vital role in the development of strategic emerging industries. By comparing the SEI policies issued by nine provinces in China, several scholars put forward suggestions for the policy-making of local governments [6]. In addition, based on industry life cycle theory, some scholars study policy objectives and measures at each stage of industrial development and build a model of SEI supporting policies in which they are classified into the policies at introduction stage, growth stage, maturity stage and adjustment stage [7].

\section{Constructing the Analytical Framework}

In the case of China, the central government plays a leading role in promoting the development of strategic emerging industries for more efficient allocation of social resources. On the other hand, industrial policy-making should follow the rules of industrial development. Therefore, this paper constructs a two-dimensional analytical framework of industrial development dimension and policy support dimension.

\subsection{Industrial Development Dimension}

It is widely assumed that industry life cycle theory comes from the product life cycle theory, proposed by the founder of marketing Theodore Levitt in his article Exploit the Product Life Cycle. Theodore believed that the life story of most successful products is a history of their passing through certain recognizable stages: Market Development, Growth, Maturity and Decline [8].

But, some scholars believe that the study of industry life cycle starts with M. Gort and S. Klepper's research on the lifecycles of 46 products, which is considered as the first attempt to develop a theory of the industry evolution [9]. Their study led to a lot of discussion about industry life cycle and gradually established the classification of the four stages of the industry life cycle [10].

The seven strategic emerging industries have their own unique characteristics and modes of development; therefore, they experience the four stages differently. From the overall perspective of industrial development, this paper regards the life cycle of strategic emerging industries as a long-term process of upgrading the industrial structure so as to further analyze the stage characteristics, common pattern and developing trend of the strategic emerging industries.

\subsection{Policy Support Dimension}

Like other industries, the life cycle of strategic emerging industries is an "endogenous evolutionary" process. However, industrial policy as an "external force" serves as a design and guidance of the evolutionary process. The importance of strategic emerging industries is reflected in science and technology, sustainable development, national defense and the promotion of other industries. Therefore, the central government became the first organizer of the development of strategic emerging industries and made related policies at different stages of industrial development.

According to the above dimensions, 40 sample policies on Chinese strategic emerging industries are sorted and categorized. I. According to the date of release, 3 policies issued by the Chinese government in 2010, 9 in 2011, 20 in 2012, and 8 in 2013 were chosen. II. Due to the fact that policy makers at different levels have different roles to play in the current political system in China, this paper divides the selected policies into 4 categories: those made by the Central Committee of the Communist Party, the State Council, the National Ministries and the inter-institutional coordination groups. III. In terms of the policy fields, the current policies involve industrial and technical support, market development, international cooperation, industrial investment and finance, tax incentives and other special policies. IV. In accordance with the policy types, the sample policies embody in various forms of laws and regulations, national plans, measures and circulations, etc. V. From the perspective of policy tools, these sample policies include three types, supply-side policy, environmental policy and demandbased policy. 


\section{Methodology}

\subsection{Research Design}

Currently, the method of content analysis as "black box technology” has been widely used in the analysis of the evolution of policies. Its advantage lies in the integrated use of quantitative and qualitative analysis methods that can measure the nature of policy texts on the keywords, issues and trends. The research thinking of this paper is as followed:

\subsection{Selecting the Sample Policies}

Since the release of the SEI Decision, a series of policies and plans have been introduced and adopted to promote the development of the seven innovative industries. The selected policies in this paper are derived from public data, mainly collected from the website of the central government's ministries and domestic innovative industry associations. The types of policies include laws, national plans, regulations, measures and circulations, etc. Altogether, they form a policy system horizontally made up of a number of sector-specific policies and longitudinally constituted by the policies issued by the central and local governments.

In order to ensure the validity and accuracy of the selection of sample policies, all the samples are screened and sorted according to the following principles: I. Policy title or content contains the keywords of "strategic emerging industries (SEI)"; II. Policy makers are the central government and its departments, that is, the macroeconomic policies at the national level are the subjects of this paper; III. Considering the large number of the special planning in the seven specific sectors, this paper only selects representative national plans; IV. Provincial SEI plans and specific measures are not within the scope of this study.

\subsection{Sorting the Texts}

Combined with the "natural coding" and "structured coding", the selected 40 sample policies were coded according to the time of release and natural properties of the policy texts (Table 1).

\subsection{Refining the Keywords}

Under the two-dimensional analytical framework of “industrial development dimension” and "policy support dimension”, this paper pre-determined 4 standardized principles and identified 26 keywords.

- To select the formal terms with high frequency to enhance the concentration of statistics.

- To select the keywords on the basis of certain hypotheses, for example, this paper intends to study the relationship between policy-makers, so "the central government”, “the local government”, “enterprises”, “stateowned enterprises”, “SMEs”, “research institutions” and “universities” are selected as certain keywords.

Table 1. Coding table of chinese strategic emerging industrial policies (2010-2013).

\begin{tabular}{|c|c|c|c|}
\hline No. & Policy items & Policy-makers & Year \\
\hline 1 & $\begin{array}{c}\text { Decision on Accelerating the Fostering and Development of Strategic } \\
\text { Emerging Industries ([2010] 32) }\end{array}$ & The State Council & 2010 \\
\hline 2 & $\begin{array}{l}\text { On the issuance of Strengthening Regional Capacity-building Industry } \\
\text { Innovation-based Guiding Significance (NDRC [2010] 2455) }\end{array}$ & NDRC $^{a}$ & 2010 \\
\hline 3 & National Economic and Social Development Twelfth Five-Year Plan & $\mathrm{CPC}^{\mathrm{b}}$ & 2010 \\
\hline 4 & Government Work Report (2011) & $\mathrm{NPC}^{\mathrm{c}}$ & 2011 \\
\hline 5 & Guiding Catalogue of Industrial Structure Adjustment (2011) & NDRC & 2011 \\
\hline$\cdots$ & $\cdots$ & $\cdots$ & $\cdots$ \\
\hline 40 & $\begin{array}{l}\text { National Resource-based Sustainable Urban } \\
\text { Development Plan (2013-2020) }\end{array}$ & The State Council & 2013 \\
\hline
\end{tabular}

a. NDRC (National Development and Reform Commission) b. CPC (the Central Committee of Communist Party). c. NPC (National People’s Congress). Source: public policy documents. 
- To code the text comprehensively, that is, try to cover all relevant entries for a more systematic and thorough research.

- To ensure that the keywords are independent of each other, for instance, "independent innovation", "innovative capacity" and "innovation development" are all incorporated into the entry of "innovation".

\subsection{Carrying out Statistical Analysis of Frequency}

On the basis of coding the policy texts, this paper carries out statistical analysis of frequency on these sample policies by applying both computational and artificial statistics. The total frequency is 6847 for all the keywords counting. This paper sorted them from the higher to lower frequency.

\section{Conclusions}

Through the frequency statistics of the above analysis show that China's SEI policies have features of focused keywords, innovation as the first key element, excessive planning and insufficiency of demand-based policy.

\subsection{Focused Keywords}

In the 26 selected keywords in sample policies on Chinese strategic emerging industries, the top 10 keywords are: Innovation, R \& D, Demonstration, Planning, Deployment, Industrialization, Intellectual Property Rights, Human Resource Training, Coordination and The Industrial Chain. The 10 words appear 5948 times, accounting for $86.87 \%$ of the total frequency of the sample keywords. The results show that the sample policies basically center on several thematic words. And the Chinese SEI policy system belongs to a relatively concentrated "discourse pedigree" (see Figure 1).

\subsection{Innovation as the First Key Element}

"Innovation" is always the focus of Chinese SEI policies. The word "innovation" occurs 1908 times, and ranks the first continuously from 2010 to 2013. "Innovation" has been reflected in various aspects, such as technology innovation, knowledge innovation, management innovation, cultural innovation, innovation capacity, innovation and development, independent innovation, original innovation, integrated innovation, innovation systems and industrial technology innovation alliances. Thus, innovation has become the first key element of the development of Chinese SEI policies.

\subsection{Excessive Planning}

Among the 40 selected Chinese SEI policies in this paper, plans account for about $50 \%$ of the total samples. Then, this paper selected the top five samples with the highest frequency. The listed below are titles, total frequency and percentage of the samples: "the National 'Twelfth Five-Year' Development Plan of Science and Technology” (763, 11.14\%), “the National 'Twelfth Five-Year' Development Plan of Independent Innovation Capability Construction” (590, 8.62\%), “the National 'Twelfth Five-Year' Development Plan of Strategic

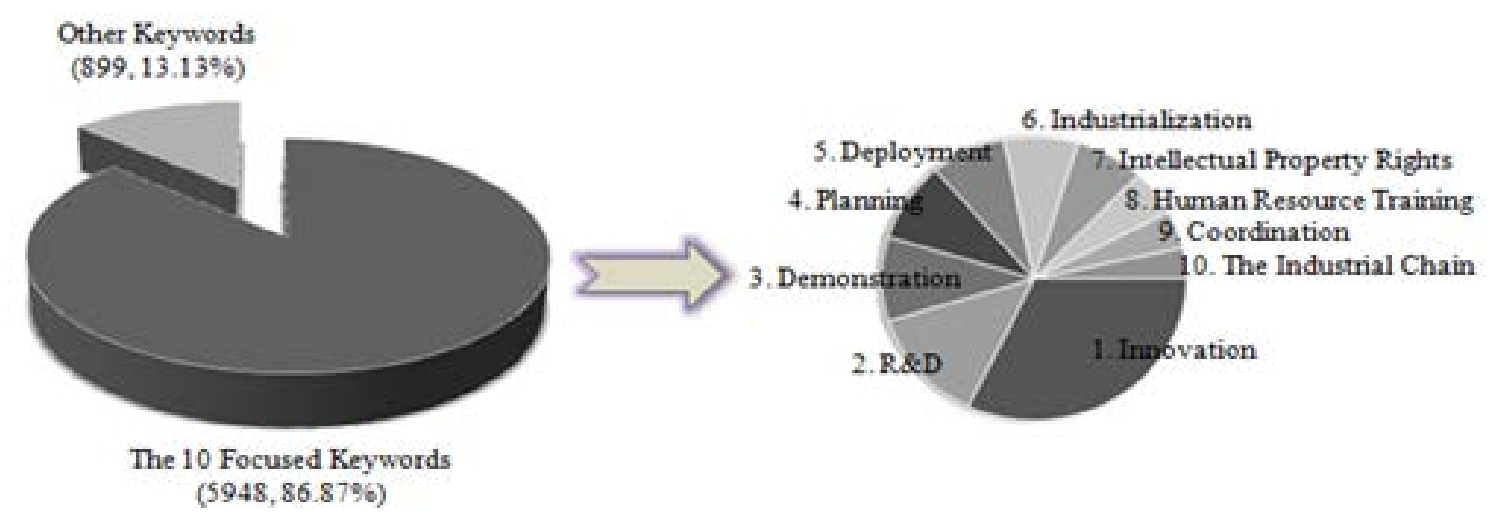

Figure 1. Statistical frequency of keywords on chinese strategic emerging industrial policies. source: author’s own. 
Emerging Industries (2012)” (505, 7.38\%), “the Industrial Restructuring and Upgrading Plan (2011-2015)” (447, 6.52\%) and "the National 'Twelfth Five-Year' Development Plan of Electronic Information Industry" (263, $3.84 \%)$.

As shown above, the objective programming and developmental plans play significant role in the early stage of Chinese strategic emerging industries, which fully reflect the guiding ideology, development principles and goals of the central government. However, these programs and plans also fully embody the distinctive characteristics of "TOP-DOWN" in Chinese political decision-making process, for instance, "Unity" and "Synchronization" may fail to take into account the regional differences, therefore in practice it is very difficult to implement the policy nationwide. Also, the various plans tend to make the policy objectives obscure and lack of focus. In addition, the National Ministries and the inter-institutional coordination groups make plans from their respective functions, which will inevitably lead to "policy content overlapping" and "unclear division of powers"..., which will undoubtedly pose many obstacles in the subsequent process of technology innovation, market development and policy improvement.

\subsection{Insufficiency of Demand-Based Policy}

Based on Rothwell and Zegveld's viewpoints, some scholars divide the basic policy instruments into three types, which are supply-side policy, environmental policy and demand-based policy. Specifically, the supply-side policy instruments usually include information technology, infrastructure and capital investment, etc. The environmental policy instruments include planning, financial support, tax incentives and regulatory control, etc.. The Demand-based policy instruments include government purchases, public service outsourcing and trade controls, etc. [11]. It shows that the majority of Chinese SEI policies belong to environmental type. To promote industrial development, the supply-side policies including human resources, capital, information and infrastructure construction also receive constant attention. In this paper, the frequency statistics of "Human Resource Training" is 317, ranks the eighth in the frequency sequence. The Ministry of Finance and NDRC set up "Strategic Emerging Industrial Development Funds" and issued management measures. However, it shows the statistical data of "Demand-based Policy" relevant to "Market Demand" and "Government Purchases" is significantly lower. This indicates that Chinese government paid more attention to promoting the environmental and supply-side SEI policies than demand-based policies. Due to the fact that the seven sectors of Chinese strategic emerging industries are at the early stage of the industry life cycle, the market demand is relatively small. Therefore, the government needs to play an active role in planning industrial development and guiding the market demand.

\section{References}

[1] The State Council (2010) Decision on Accelerating the Fostering and Development of Strategic Emerging Industries. http://www.gov.cn/zwgk/2010-10/18/content_1724848.htm

[2] Research Topics of Reform Magazine (2011) The Strategic Emerging Industry: Policy Evolution and Theory Innovation. Chongqing Social Sciences, 1, 46-51.

[3] Zhang, Y.Z. and Wang J.F. (2011) Policy Review of Fostering Strategic Emerging Industry. Scientific Management Research, 29, 1-6.

[4] Hu, S.Q., Zhan Z.M., Qian, R. and Zhang, F. (2013) Studies on the Policy Instrument System about Developing of Strategic Emerging Industry-Based on Content Analysis of Policies. Scientific Management Research, 31, 66-69.

[5] Zeng, F.H., Peng, Z. and Chen, X. (2013) Review and Evaluation of the Latest Development of Strategic Emerging Industries Policy. Science \& Technology Progress and Policy, 30, 155-160.

[6] Dong, X.Y. and Tang, S.S. (2013) Comparison of Local Government Policy on the Development of Strategic Emerging Industries. Science \& Technology Progress and Policy, 30, 119-123.

[7] Fei, Z.L. and Wei, W. (2013) Government Policies to Support Strategic Emerging Industries—Based on the Consideration of Industry Life Cycle. Science \& Technology Progress and Policy, 30, 104-107.

[8] Theodore Levitt. (1965) Exploit the Product Life Cycle. Harvard Business Review, 43, 81-94.

[9] Gort, M. and Klepper, S. (1982) Time Paths in the Diffusion of Product Innovations. The Economic Journal, 92, 630653. http://dx.doi.org/10.2307/2232554

[10] Zhang, H.H. (2004) On the Theory of Industry Life Cycle. Finance and Trade Research, 6, 7-11.

[11] Huang, C., Su, J., Shi, L.P. and Cheng, X.T. (2011) Textual and Quantitative Research on Chinese Wind Energy Policy System from the Perspective of Policy Tools. Studies in Science of Science, 29, 876-889. 